\title{
Porous Bioglass Scaffold for Orthopedics Applications
}

\author{
Stephanie SOARES ${ }^{1}$, Abílio SILVA ${ }^{1}{ }^{*}$, Ilídio CORREIA ${ }^{2}$ \\ ${ }^{1}$ C-MAST, UBI, Centre for Mechanics and Aerospace Science Technologies, University of Beira Interior, 6200-001 \\ Covilhã, Portugal \\ ${ }^{2}$ CICS, UBI, Health Sciences Research Centre, University of Beira Interior, 6200-001 Covilhã, Portugal \\ cross ${ }^{\text {ref }}$ http://dx.doi.org/10.5755/j01.ms.22.2.8581
}

Received 30 October 2014; accepted 08 March 2015

\begin{abstract}
This work aims to contribute for the development of bioglass scaffolds to be used in bone tissue regeneration. Starting from the classic quaternarian composition of the bioglass $45 \mathrm{~s} 5$ it was added potassium oxide and magnesium oxide in order to obtain the optimised system: $\mathrm{SiO}_{2}-\mathrm{CaO}-\mathrm{Na} 2 \mathrm{O}-\mathrm{MgO}-\mathrm{K}_{2} \mathrm{O}-\mathrm{P}_{2} \mathrm{O}_{5}$, improving the mechanical resistance and the bioactivity behaviour. The mixture was reached by a fusion at $1500{ }^{\circ} \mathrm{C}$ followed by thermal shock, the resulting bioglass was milled to get a particle size less than $40 \mu \mathrm{m}$ and it was homogenised with a porogen agent (salt), resulting the pressed specimens at $100 \mathrm{MPa}$ of 100, 60, 50, and $40 \mathrm{wt} . \%$ of bioglass. After sintering, bleaching and maturation, it was evaluated the mechanical behaviour, toxicity and bioactivity, proving the viability and potential of this simplified method of scaffold's manufacture, also putting in evidence the advantages of the using salt as a porogen agent in the morphology and structure obtained.

Keywords: porous bioglass, salt, scaffolds, tissue engineering.
\end{abstract}

\section{INTRODUCTION}

Currently, the medicine in synergy with tissue engineering has been growing towards building porous scaffolds in order to repair or replace the bone tissue. In this study, we aim to construct a biomaterial reactive with high mechanical properties in order to be able to replace both the cortical and trabecular bone.

The need of the bone tissue reconstruction promoted the progress of new biomaterials capable of replacing or optimizing traditional processes, designated as grafts. Synthetic biomaterials, such as calcium phosphates, present with controlled physico-chemical properties are considered a good alternative to grafts from other origins. These materials create a stable connexion with the neoformed bone. Examples of these are the hydroxyapatite (HA), calcium triphosphate and the bioglasses [1-3].

Ceramics like hydroxyapatite $\left(\mathrm{HA}-\mathrm{Ca}_{10}\left(\mathrm{PO}_{4}\right)(\mathrm{OH})_{4}\right)$ and calcium phosphates were initially used in orthopedic field, namely biphasic calcium phosphate (BCP) and tricalcium phosphate (TCP), which stood out for the favourable properties: biocompatibility, due to the high chemical and structural similarities with the bone; bioinert; they create a porous structure, which facilitates cells infiltration and favors bone tissue growth $[1,4,5]$. However, these materials present several disadvantages that limit its use: brittleness, the difficulty to get a form to its implementation, the absence of structural holder brought about the fast reabsorption due to the macroporosity [6].

The bioactive glasses appeared in the 1960's and are used in the orthopedic field, such as periodontal applications and maxillofacial and skull surgery, as it is the case of the quaternarian glass $\mathrm{SiO}_{2}-\mathrm{CaO}-\mathrm{Na}_{2} \mathrm{O}-\mathrm{P}_{2} \mathrm{O}_{5}$ (Bioglass 45s5), which promote a chemical connection

\footnotetext{
${ }^{*}$ Corresponding author. Tel.: +351-275-329913; fax: +351-275-329972

E-mail address: abilio@ubi.pt (A. Silva)
}

through an apatitic bond with bone tissue and it presents excellent similarities with a trabecular bone [7]. In contact with body fluids, bioglasses enable HA deposition by stimulating a bonding function and ions controlled liberation, which promote cell proliferation with a consequent bone tissue formation. The high cells number of the trabecular bone and its high porosity (up to $80 \%$ ) are responsible for the high metabolic activity, promoting a fast modelling of the bone. However, several studies present limitations to the classical composition of bioglass $45 \mathrm{~s} 5$, but these can be improved by the addition of network modifiers oxides [8-10].

To mimic bone tissue is necessary to consider three key properties to reach values similar to bone, which are the bioactivity, mechanical properties and microstructure. Bioactivity of biomaterial is attributed to the formation of a HA polycrystalline layer on the bioglass surface in a physiological environment, which is influenced by the composition of the biomaterial. The constituent ions of bioglass 6P53-b are involved in bone metabolism, in mineralization process and in angiogenesis [11-13].

On the other hand, the mechanical properties depend on the composition of the material microstructure and sintering process. The addition of magnesium oxide $(\mathrm{MgO})$, justified as being one of the cortical bone constituent, allows an improvement in the cellular adhesion by promoting, during the thermal treatment, the strengthening of the layer. This is one advantage of the using a bioglass in the coating of metallic prosthesis, avoiding a too fast absorption of the bioglass, not allowing the substrate to touch the surrounding tissue and avoiding its possible displacement. The addition of sodium oxide $(\mathrm{NaO})$ allows to increase chemical durability and potassium oxide $\left(\mathrm{K}_{2} \mathrm{O}\right)$ induces an increase in the devitrification of the network that favorable in bioactivity. In turn, the porogen agent allows to provide stability and maintain shape of the macropores to the densification 
process occurs that during sintering which will lead to a strengthening of trabecular on synthesis process [14-16].

To obtain a macro porous microstructure it is crucial to use the porogen type since this provides the size and shape of porosity. One of the conventional methods used in creating porosity is the use of a porogen agent soluble during final processing (sintering or leaching), due to its low melting point or high solubility is removed providing the size and shape of macropores. Salt is a porogen agent very easy to remove and does not affect the conformation of the matrix, unlike most polymers due to their hydrophobicity are difficult to remove $[17-21]$. On the other hand, increasing the temperature for melting the polymer can modify the conformation of the matrix due to the crystallization effects. In addition, low chemical reactivity of the polymers due to its polarity, reduces the bioactivity of the biomaterial [18].

In this work the optimized composition of bioglass (6P53-b) is mixed with a porogen element (salt) resulting in a pore shape similar to the trabecular bone tissue, while promoting a resistant net during the sintering process and obtaining a more resistant structure especially after the maturation process. This bioglass material can be applied in the field of orthopedics such as: bone substitute; in surgery maxillofacial and periodontal; bone defects in that arise, due to trauma, bone loss, as well as on coating of prostheses in order to avoid contact between the substrate and the surrounding tissue which is the reason for the high number of infections and reducing the number of micromovements by fixing the prosthesis.

\section{MATERIALS AND METHODS}

Silicon dioxide $\left(\mathrm{SiO}_{2}\right.$, Sigma-Aldrich, Spain), calcium oxide (CaO, Sigma-Aldrich, Spain), magnesium oxide (MgO, J. Vaz Pereira, Portugal), sodium oxide $\left(\mathrm{Na}_{2} \mathrm{O}\right.$, Sigma-Aldrich, Spain), phosphorus pentoxide $\left(\mathrm{P}_{2} \mathrm{O}_{5}\right.$, Sigma-Aldrich, Spain) and potassium carbonate $\left(\mathrm{K}_{2} \mathrm{CO}_{3}\right.$, Sigma-Aldrich, Spain) were used as ingredients of the bioglass "6P53-b", in the proportions of 51, 19, 15, 9.8, 2.5 and $1.8 \mathrm{wt} \%$, respectively. They were mixed (homogenized) and fused on a crucible at $1500{ }^{\circ} \mathrm{C}$, during 30 minutes, with a heating rate of $5{ }^{\circ} \mathrm{C} /$ minute, the mixture was then poured in water at room temperature to promote an abrupt cooling and avoid the crystallization, thus obtaining amorphous bioglass.

The bioglass was ground on a ball mill to get particles of a size less then $40 \mu \mathrm{m}(\mathrm{d} 90<36.3 \mu \mathrm{m})$, obtained from size 325 mesh sieve (Restch, according to DIN-ISO 331011) and controlled with a laser particle analyzer, Coulter LS200. The mixture, using a binder (acetone) with salt (porogen), at sizes between 212 and $425 \mu \mathrm{m}$ (sieves of 70 and $40 \mathrm{mesh}$ ), was performed at the ratio of 100, 60, 50 and $40 \mathrm{wt} . \%$ and pressed (double effect) in a rigid matrix (316L stainless steel) at $100 \mathrm{MPa}$ for 1 minute.

The samples were dried at room temperature for $24 \mathrm{~h}$ and sintered at $725^{\circ} \mathrm{C}$ for 3 hours, with heating rate of $5^{\circ} \mathrm{C} /$ minute. The parameters of the cycle of sintering were determined after a DTA (differential thermal analysis) of the bioglass to guarantee amorphous specimens. The macroporosity obtained after bleaching the crystals of salt in thermostatic bath, Selecta Unitronic S320-100, with distilled water jet at $50{ }^{\circ} \mathrm{C}$ for 12 hours. Then the scaffold place submersed in distilled water for one week (maturation process).

The porosity was analysed through porosimetry by intrusion of mercury (PIM), Autopore IV, model 9220 of Micrometrics Instrument. Also it was done interconnectivity tests to evaluate the existence of channels which interconnect the pores. The mechanical tests of compression were done with a universal Zwick's test machine, type 1435 , with load cell up to $5 \mathrm{KN}$. Statistical analysis of the mechanical tests was obtained with a minimum of four independent and significant samples with dimensions of approximately $6 \mathrm{~mm} \times 7 \mathrm{~mm}$.

The compounds values in the composition after the fusion and the thermal shock were confirmed through elementary analysis using SEM, Hitachi s-2700, with EDX module. An analysis of the homogeneity of the trabecular porous net of sample it was done through SEM images, by visualising the anchoring of the bioglass cells, the HA layer at the biomaterial surface (presence of HA by the variation of calcium and phosphorus ions). Using analysis of X-ray diffraction (XRD), Rigaku model DMAXIII/C, it proved that after sintering of the scaffolds of bioglass "6P53-b" it was amorphous [22].

Human osteoblastic cells were put into $23 \mathrm{~cm}^{3}$ T-flasks with DMEM-F12 supplemented with heat inactivation and antibiotic/antimycotic solutions. When the cells reached confluence, they were subcultivated by incubation in Trypsin and EDTA for 3-5 minutes. Then the cells were centrifuged, resuspended in culture and put into a $75 \mathrm{~cm}^{3} \mathrm{~T}$-flasks. Throughout this process, the cells were kept at $37^{\circ} \mathrm{C}$ in a humidified atmosphere of $5 \%$ of $\mathrm{CO}_{2}$ in an incubator $[23,24]$.

Human osteoblastic cells were cultivated in direct contact with small irregular pieces of bioglass in a 96-well plate, each formulation was added $(n=4)$, at a density of $15 \times 103$ cells/well. After the incubation period (24, 48 and 72 hours), cell viability was evaluated by reduction of MTS into a solution of formazan and water. The absorbance of the formazan was measured at $492 \mathrm{~nm}$ using a microplate reader (Sanofi, Pauster Diagnostics). The wells containing the cells in culture without bioglass samples were used as negative control $\left(\mathrm{K}^{-}\right)$. The wells containing cells was added ethanol (96\%) corresponding to the positive control $\left(\mathrm{K}^{+}\right)$. Cellular growth was monitored using an Olympus inverted light microscope, type CX41. These results presented are the mean \pm standard deviation of at least five independent experiments. Statistical analysis was performed using one-way ANOVA with confidence of $95 \%$.

The bioactivity of the bioglass samples was evaluated in vitro by observing the deposition of a layer of silica gel on the surface of each test piece to $100 \%, 60 \%, 50 \%$ and $40 \%$ of bioglass after various immersion times in SBF. SBF was prepared in laboratory according to the protocol of Kokubo. Mineralization by the deposition tests were carried hydroxycarbonateapatite (HCA) leached by immersing samples in SBF to 1.7, 14, 21 and 28 days. To evaluate the deposition of HCA, samples were characterized after different periods of immersion by SEM and EDX to analyse quantitatively and morphologically HCA. 


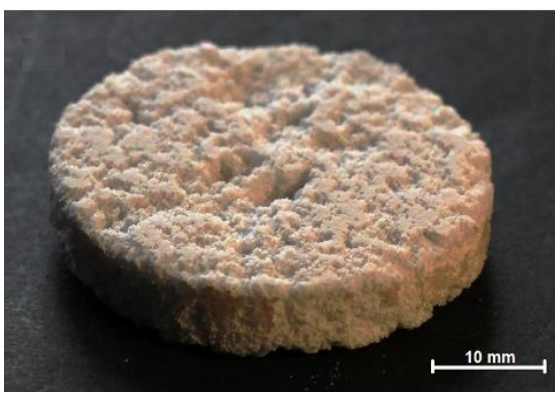

a

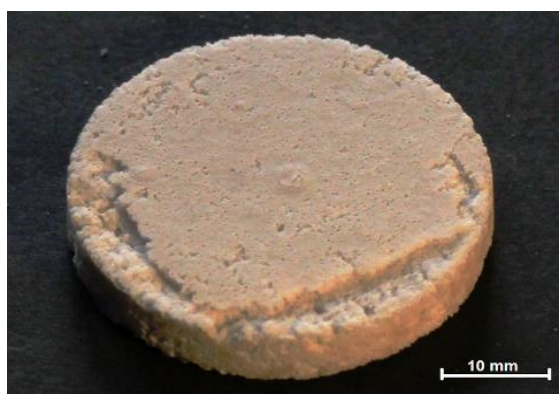

b

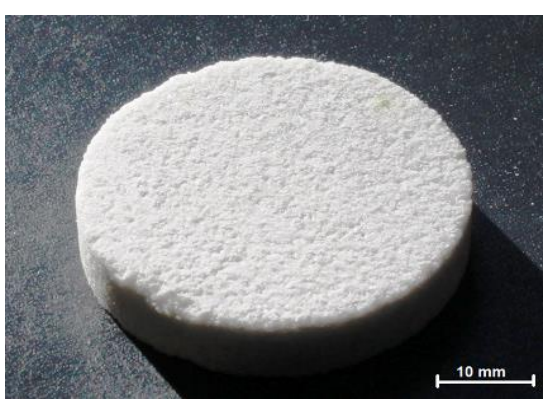

Fig. 1. Evolution of the specimens quality in function of the manufacture methodology optimization (homogenization, mould, acetone added): $a$-scaffold with cavities in the surface after the bleaching; $b$-differences in the homogeneity after sintering, delamination; $\mathrm{c}$ - scaffolds with an optimized mixture process

During immersion, it is carried out systematically $\mathrm{pH}$ evaluation of each solution, so the $\mathrm{pH}$ variation promoted by the ion exchange between the SBF and bioglass was monitored.

\section{RESULTS AND DISCUSSION}

The synthesis of bioglass "6P53-b" yielded the raw material required for this work, without the need to purchase, and the proportions of ingredients was repeatedly confirmed by EDS. After thermal shock there has been no change in the properties of the bioglass as to its transparency and translucency.

The sintering cycle was determined after DTA of the bioglass to guarantee amorphous specimens, $\mathrm{T}=725^{\circ} \mathrm{C}$, since it allows complete densification of bioglass, avoid the crystallization phenomena that impair the bioactivity. Fig. 1 shows the evolution of the specimens during the optimization of the manufacture method. Fig. 1 a shows the scaffold with cavities in the surface after the bleaching; this is the result of a mixture with reduced homogeneity and excessive superficial agglomeration of salt. Fig. $1 \mathrm{~b}$ shows the differences in the homogeneity after sintering (delamination) caused by segregation as result of the excess of binder (acetone higher than $20 \mathrm{wt} . \%$ ). Fig. $1 \mathrm{c}$ shows the scaffolds with an optimized mixture process. The optimization of the manufacture method requires a homogenizing of the bioglass powders mixture, the quantity of added acetone, the compaction pressure in the molds and the sintering cycle without the crystallization of the bioglass samples. After obtaining the samples of bioglass it was proved by XRD its amorphous state. The Avrami crystallization kinetics for the bioglass samples is equal to $107.5 \mathrm{~kJ} / \mathrm{mol}$ and the corresponding value of $n=1$, which means that the crystallization tends to occur preferentially at the surface [25]. Fig. 2 shows, at low magnification, SEM morphology and macroporosity in the $100 \%$ bioglass samples, Fig. 2 a, and also in the samples with different relations of bioglass/salt of 60/40, Fig. 2 b, 50/50, Fig. 2 c, and 40/60, Fig. 2 d. Fig. 2 a only shows the porosity coming from the particles packing of the $100 \%$ bioglass and origin during the sintering cycle to obtain a non-crystalline sample. Fig. 2 b, c and d shows that the increase of salt addition leads to the formation of a porous network of a cubical shape structure with well defined boundaries.

Fig. 3 shows, at high magnification, a detailed porous network shape, the thickness of its boundaries, the roughness and the sintering degree of the interconnecting bond. As expected, higher content of the porogen agent higher is the porosity of the sample. However, it is important to underline that the $100 \%$ of bioglass samples show microporosity $(\sim 6.5 \mu \mathrm{m})$ explained by the imperfect packing of the particles distribution and by the sintering process to a value lower than the crystallization temperature.

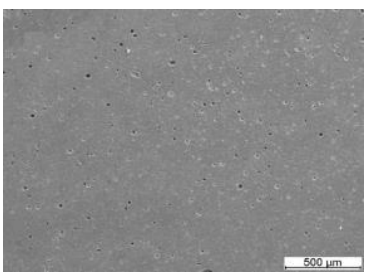
a

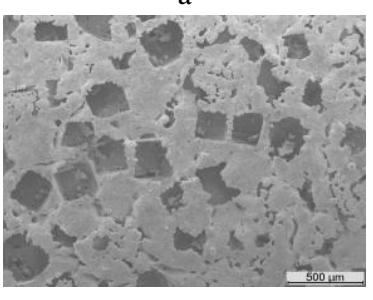

c

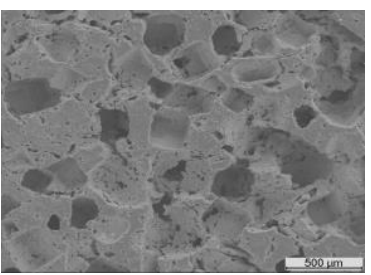

b

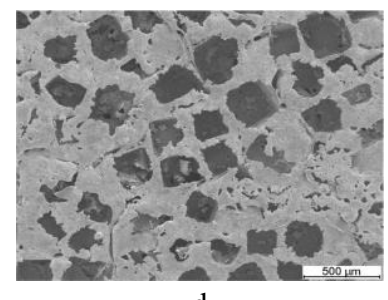

d
Fig. 2. SEM surfaces at low magnification (50x) for the samples: $\mathrm{a}-100 \%$ bioglass; $\mathrm{b}-60 \%$ bioglass; $\mathrm{c}-50 \%$ bioglass; $\mathrm{d}-40 \%$ bioglass

Fig. 3 a shows a spherical interstice of the sample of the $100 \%$ bioglass and Fig. $3 \mathrm{~b}$ shows a high similarity between the porous network, obtained through the action of the porogen agent and the network of the trabecular bone.

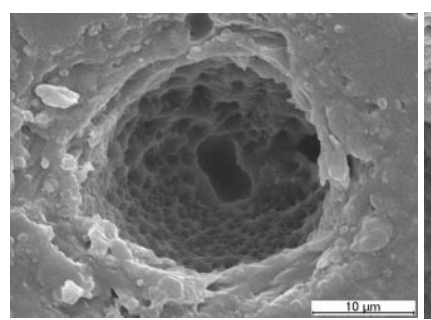

a

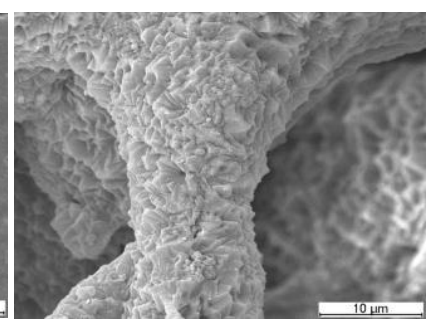

$\mathrm{b}$
Fig. 3. SEM surfaces at high magnification (1000x) for the samples with: $\mathrm{a}-100 \%$ bioglass; $\mathrm{b}-60 \%$ bioglass

A special emphasis goes to the result as being a porous network, which adds the interstitial porosity of $100 \%$ bioglass with the porosity left by the salt during the sintering cycle and roughness, resulting in the presence of 
well-defined trabecular and showing high densified and have high strength which will facilitate the cellular anchoring and the homogeneous distribution of the porosity with similar size and shape to the trabecular bone.

The permeability of the sample bioglass, as well as the interconnectivity of the pores was examined visually by velocity of capillary adsorption of liquid dye (methylene blue), and quantified by the method of Archimedes, Table 1, where it occurs a gradual reduction of the bulk density $\left(\mathrm{BD}, \mathrm{g} / \mathrm{cm}^{3}\right)$ and a growing water absorption (WA, \%) of the samples with the increase of salt content.

The porosity tests show that for the samples with higher bioglass tenor there is a bigger intrusion of mercury (more porous samples), because there is an expansion of the open pores area and an increase of the pore average diameter from $6.5 \mu \mathrm{m}$ to $88 \mu \mathrm{m}$, correspond to the microporosity of the $100 \%$ of bioglass samples and the macroporosity of the $40 \%$ of bioglass samples, respectively.

Table 1. Properties of the bioglass samples

\begin{tabular}{|l|c|c|c|c|}
\hline Bioglass, \% & 100 & 60 & 50 & 40 \\
\hline $\mathrm{BD}, \mathrm{g} / \mathrm{cm}^{3}$ & 2.61 & 1.10 & 0.87 & 0.76 \\
\hline $\mathrm{WA}, \%$ & 0.73 & 36.0 & 53.0 & 73.5 \\
\hline Volume of intrusion, $\mathrm{mL} / \mathrm{g}$ & 0.059 & 0.397 & 0.770 & 0.996 \\
\hline Area of porous, $\mathrm{m}^{2} / \mathrm{g}$ & 0.001 & 0.030 & 0.055 & 0.065 \\
\hline Average size of porous, $\mu \mathrm{m}$ & 6.52 & 64.07 & 85.94 & 88.16 \\
\hline
\end{tabular}

Bone tissue does not have porosity with the same magnitude. There are a net of large pores and also very small cavities. In the samples produced a macro porosity with a distribution between 40 to $150 \mu \mathrm{m}$ it is provide by the porogen agent (salt) while the micro porosity of 0.5 to $10 \mu \mathrm{m}$ is caused by the particle size distribution of bioglass raw materials and by the sintering conditions. The average pore size is close to the $90 \mu \mathrm{m}$. The dimension of the porous network is less than the desired, because during the sintering process and consequent densification of the bioglass structure it is observed a reduction of salt grains. This can be improved by the increase in the average size of the granulometric distribution of the porogen element (salt).

A higher mechanical resistance is obtained in the samples with higher bioglass percentage, because they have a higher mechanical compression resistance due to trabecular of higher density. An efficient way to increase the compression mechanical resistance is to improve the quality of microstructure by increasing the density and decreasing the intergranular fissures (defects) through maturation methodology. Thus, maturation has promoted the structural development, coalescing reactions, dissolution and subsistence with the expulsion of the residual salt, improving the mechanical strength due to the minimization of the surface fissures and the foundation of crosslinks, observing a continued hardening of the bioglass matrix [26, 27].

The literature refer to compression mechanical resistance between $2-12 \mathrm{MPa}$ for the trabecular bone $[16,24,26,28]$. The results for the samples with maturation are within this interval, except for the $40 \%$ bioglass, but when comparing the mechanical compression strength of this sample with higher porosity (around $90 \%$ ) with similar samples of the traditional bioglass $45 \mathrm{~s} 5$, it was obtained a mechanical compression strength values about $50 \%$ higher $[12,14,15]$.

The increase in mechanical strength is proportional to the increase of deformation, so observing a lower slope in the first part of the test (Young's modulus lower) to first collapse of the trabecula, more fragile, of interconnecting between pores (point 1, Fig. 4). Follow a new gradual increase of the resistance supported by the trabecular network of the sample with greater rigidity (Young's modulus higher) until the maximum strength and the following catastrophic rupture of the structure (point 2, Fig. 4).

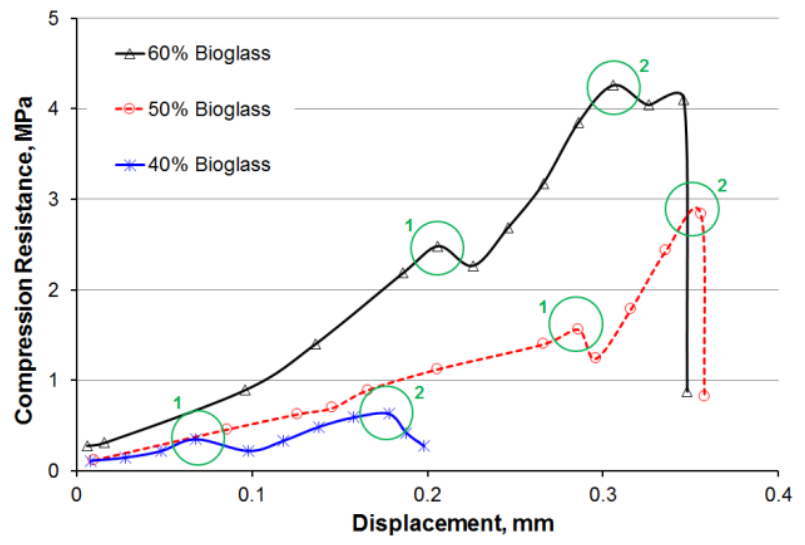

Fig. 4. Typical mechanical behaviour in compression of bioglass scaffolds

The implementation of the maturation process after the samples sintering and its bleaching are factors", which induce a higher mechanical strength (improvement of $16 \%$ ); however, also it is important the bioglass composition and the cubic shape of the pore caused by the use of salt as porogen and principally the densification of the bioglass structure (trabecular network) during the sintering cycle [26, 29].

Through biological evaluation, by visualizing the adherence and cellular growth in all samples, it can be seen that all materials are biocompatible. The characterization of cytotoxic agents through MTS tests, Fig. 5, evidenced that the cells in contact with the bioglass samples had similar viability as the negative control one $[23,30]$.

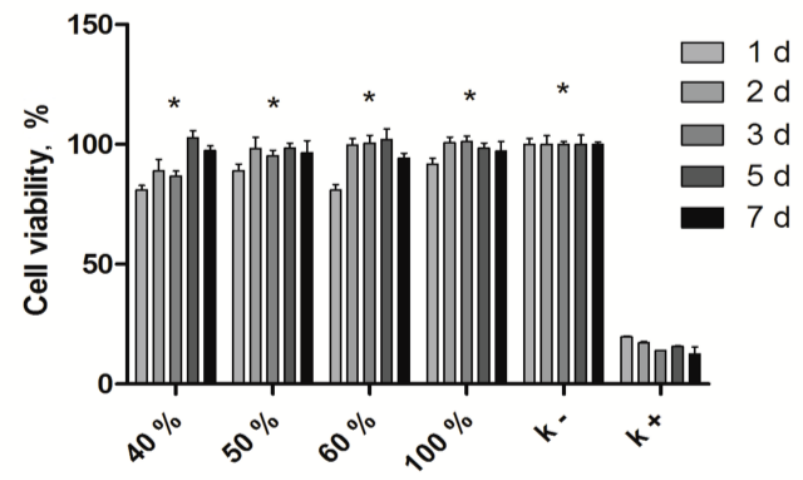

Fig. 5. Cellular viability after 1, 2, 3, 4, 5, 6 and 7 days compared to the negative control $\left(\mathrm{K}^{-}\right)$, positive control $\left(\mathrm{K}^{+}\right)$of the bioglass samples of $100 \%, 60 \%, 50 \%$ and $40 \%$

Furthermore, statistical analysis conducted for 7 day results show a statistically significant difference between the positive control of the cells exposed to bioglass and the negative control (with a statistically significancy adopted 
for a p-value less than 0.001), proving that all samples are good candidates to biomedical applications. EDX analysis of the sample of $40 \%$ bioglass, quantifies that the $\mathrm{CA} / \mathrm{P}$ ratio is close to 1.3 , corresponding to octacalcium phosphate $\left(\mathrm{Ca}_{8} \mathrm{H}_{2}\left(\mathrm{PO}_{4}\right) 6.5 \mathrm{H}_{2} \mathrm{O}\right)$. This metastable phase is a precursor of the HA phase $(\mathrm{Ca} / \mathrm{P}=1.67)[31,32]$.

\section{CONCLUSIONS}

A simplified method was used to obtain a raw material of bioglass composition, known in literature, with the designation of bioglass "6P53-b". After mixed and homogenized with the porogen agent and the right amount of binder, it was obtained porous disks samples of bioglass by double effect pressure. Controlled sintering to obtain amorphous structures and bleaching process were appropriate to the achievement of high porosity network. The maturation process of the bioglass samples enabled a great improvement of the mechanical resistance and a microstructure with smaller number of defects and higher densification of the trabecular.

The amount of $40 \%$ of bioglass presents itself as a minimum limit due to the low mechanical resistance and the later absence of structural support. The compression resistance to the bioglass samples with maturation is inside of the values of the trabecular bone, except the $40 \%$ bioglass sample, whose properties can be improved by adding reinforcement (fibers). Ever these samples (of higher porosity) have got a mechanical resistance $50 \%$ higher than similar traditional bioglass (45s5).

The cellular viability evidenced that the cells in contact with the bioglass samples had similar viability as the negative control, of all samples, inducing to cellular proliferation and superficial reactivity for the deposition of an HA intermediate, showing a good aptitude to a future in vitro analysis.

This work contributed to the implementation of new synthesis techniques in order to obtain bioglass raw materials and added salt as porogen to promote macro porosity. The preliminary results show a path for further research focused on improve the chemical reactivity by optimizing the composition and improved of the mechanical properties of the scaffold to achieve the bone tissue values.

\section{REFERENCES}

1. Ducheyne, P., Qiu, Q. Bioactive Ceramics: The Effect of Surface Reactivity on Bone Formation and Bone Cell Function Biomaterials $20(23-24)$ 1999: pp. $2287-$ 2303.

2. Dorozhkin, S. V. Calcium Orthophosphates as Bioceramics: State of the Art Journal of Functional Biomaterials 1 (1) 2010: pp. 22-107. http://dx.doi.org/10.3390/jfb1010022

3. Midha, S., van den Bergh, W., Kim, T. B., Lee, P. D., Jones, J. R., Mitchell, C. A. Bioactive Glass Foam Scaffolds are Remodelled by Osteoclasts and Support the Formation of Mineralized Matrix and Vascular Networks In Vitro Advance Healthcare Materials 2 (3) 2013: pp. 490-499.

4. Emadi, R., Roohani, S., Esfahani, S., Tavangarian, F. A Novel, Low Temperature Method for the Preparation ofTCP/HAP Biphasic Nanostructured Ceramic Scaffold
From Natural Cancellous Bone Materials Letters

$64(8)$

2010: pp. $993-996$.

http://dx.doi.org/10.1016/j.matlet.2010.01.085

5. Nezafati, N., Moztarzadeh, F., Hesaraki, S., Mozafari, M. Synergistically Reinforcement of a Self-setting Calcium Phosphate Cement with Bioactive Glass Fibers Ceramic International 37 (3) 2011: pp. 927-934.

6. Xu, H. H. K., Weir, M. D., Burguera, E. F., Fraser, A. M. Injectable and Macroporous Calcium Phosphate Cement Scaffold Biomaterials 27 (24) 2006: pp. 4279-4287.

7. Hench, L. L. The Story of Bioglass Journal of Materials Science: Materials in Medicine $17(11)$ 2006: pp. $967-978$. http://dx.doi.org/10.1007/s10856-006-0432-z

8. Rahaman, M. N., Fu, Q., Bal, B. S., Day, D. E., Fu, H. Bioactive Glass for Bone and Joint Repair Ceramic Transactions 218 2010: pp. 85-100.

9. Emadi, R., $\quad$ Tavangarian, F., $\quad$ Esfahani, S. I. R. Biodegradable and Bioactive Properties of a Novel Bone Scaffold Coated with Nanocrystalline Bioactive Glass for Bone Tissue Engineering Materials Letters 64 (13) 2010: pp. $1528-1531$.

10. Rahaman, M. N., $\quad$ Day, D. E., $\quad$ Bal, B. S., $\quad$ Fu, Q., Jung, S.B., Bonewald, L. F., Tomsia, A. P. Bioactive Glass in Tissue Engineering Acta Biomaterialia 7 (6) 2011: pp. 2355-2373.

11. Hoppe, A., Guldal, N. S., Boccaccini, A. R. A Review of the Biological Response to Ionic Dissolution Products from Bioactive Glasses and Glass-ceramics Biomaterials 32 (11) 2011: pp. 2757-2774.

12. Vitale-Brovarone, C., Baino, F., Verne, E. Feasibility and Tailoring of Bioactive Glass-ceramic Scaffolds with Gradient of Porosity for Bone Grafting Journal of Biomaterials Application 24 (8) 2010: pp. 693-712.

13. Goodall, R., Despois, J. F., Mortensen, A. Sintering of $\mathrm{NaCl}$ Powder: Mechanisms and First Stage Kinetics Journal of European Ceramic Society 26(16) 2006: pp. $3487-3497$. http://dx.doi.org/10.1016/j.jeurceramsoc.2005.12.020

14. Bellucci, D., Cannillo, V., Ciardelli, G., Gentile, P., Sola, A. Potassium Based Composition for a Bioactive Glass Ceramic International $36(8)$ 2010: pp. $2449-$ 2453.

15. Bellucci, D., Cannillo, V., Sola, A. A New Potassiumbased Bioactive Glass: Sintering Behaviour and Possible Applications for Bioceramic Scaffolds Ceramic International 37 (1) 2011: pp. 145-157.

16. Huan, Z., Zhou, J., Duszczyk, J. Magnesium-based Composites with Improved in Vitro Surface Biocompatibility Journal of Materials Science: Materials in Medicine 21 (12) 2010: pp. 3163-3169. http://dx.doi.org/10.1007/s10856-010-4165-7

17. Murphy, W. L., Dennis, R.G., Kileny, J.L., Mooney, D.J., Salt Fusion: an Approach to Improve Pore Interconnectivity Within Tissue Engineering Scaffolds Tissue Engineering 8 (1) 2002: pp. $43-52$.

18. Tadic, D., Beckmann, F., Schwarz, K., Epple, M. A Novel Method to Produce Hydroxyapatite Objects with Interconnecting Porosity that Avoids Sintering Biomaterials 25 (16) 2004: pp. 3335-3340.

19. Liang, W., Rüssel, C. Resorbable, Porous Glass Scaffolds by a Salt Sintering Process Journal Materials Science 41 (12) 2006: pp. 3787-3792. 
20. Tran, R. T., Naseri, E., Kolasnikov, A., Bai, X. C., Yang, J. A New Generation of Sodium Chloride Porogen for Tissue Engineering Biotechnology and Applied Biochemistry 58 (5) 2011: pp. 335-344.

21. Li, J., Bryan-Baker, A., Mou, X., Ren, N., Qiu, J., Boughton, R. I., Liu, H. Biopolymer/Calcium Phosphate Scaffolds for Bone Tissue Engineering Advance Healthcare Materials 3 (4) 2014: pp. 469-484.

22. Verné, E., Bretcanu, O., Balagna, C., Bianchi, C. L., Cannas, M., Gatti, S., Vitale-Brovarone, C. Early Stage Reactivity and in Vitro Behavior of Silica-based Bioactive Glasses and Glass-ceramics Journal Materials Science: Materials in Medicine 20 (1) 2009: pp. 75-87. http://dx.doi.org/10.1007/s10856-008-3537-8

23. Maia, J., Ribeiro, M. P., Ventura, C., Carvalho, R. A., Correia, I. J., Gil, M. H. Ocular Injectable Formulation Assessment for Oxidized Dextran-based Hydrogels Acta Biomaterialia 5 (6) 2009: pp. 1948 - 1955.

24. Santos, C. F. L., Silva, A. P., $\quad$ Lopes, L., Pires, I., Correia, I. J. Design and Production of Sintered BTricalcium Phosphate 3D Scaffolds for Bone Tissue Regeneration Materials Science and Engineering: $C$ 32 (5) 2012: pp. $1293-1298$.

25. Fokin, V. M., Zanotto, E. D., $\quad$ Yuritsyn, N. S., Schmelzer, J. W. P. Homogeneous Crystal Nucleation in Silicate Glasses: a 40 Years Perspective Journal of NonCrystalline Solids 352 (26-27) 2006: pp. 2681-2714.

26. Daglilar, S., Erkan, M., Gunduz, O., Ozyegin, L. S., Salman, S., Agathopoulos, S., Oktar, F. N. Water
Resistance of Bone-cements Reinforced with Bioceramics Materials Letters $61(11-12)$ 2007: pp. 2295-2298.

27. Hammouda, I. M. Reinforcement of Conventional Glassionomer Restorative Material with Short Glass Fibers Journal of the Mechanical Behavior of Biomedical Materials 2 (1) 2009: pp. $73-81$.

28. Ozgür-Engin, N., Tas, A. C. Manufacture of Macroporous Calcium Hydroxyapatite Bioceramics Journal of European Ceramic Society 19 (13-14) 1999: pp. 2569-2572.

29. Sola, A., Bellucci, D., Raucci, M. G., Zeppetelli, S., Ambrosio, L., Cannillo, V. Heat Treatment of $\mathrm{Na}_{2} \mathrm{O}-\mathrm{CaO}-$ $\mathrm{P}_{2} \mathrm{O}_{5}-\mathrm{SiO}_{2}$ Bioactive Glasses: Densification Processes and Postsintering Bioactivity Journal of Biomedical Materials Research Part A 100A (2) 2012: pp. 305-322. http://dx.doi.org/10.1002/jbm.a.33276

30. Torres, A. L., Gaspar, V. M., Serra, I. R., Diogo, G. S., Fradique, R., Silva, A. P., Correia, I. J. Bioactive Polymeric-ceramic Hybrid 3D Scaffold for Application in Bone Tissue Regeneration Materials Science and Engineering: C 33 (7) 2013: pp. 4460-4469.

31. Zarkoob, H., Ziaei-Rad, S., Fathi, M., Dadkhah, $\mathbf{H}$. Synthesis, Characterization and Bioactivity Evaluation of Porous Barium Titanate with Nanostructured Hydroxyapatite Coating for Biomedical Application Advance Engineering Materials 14 (6) 2012: pp. B322-B329.

32. Drouet, C. Apatite Formation: Why it May Not Work as Planned, and How to Conclusively Identify Apatite Compounds BioMed Research International 2013: Art. Number 490946. 